\title{
Chains in Chains - Logic and Challenges of Blockchains in Supply Chains
}

\author{
Henrik Sternberg \\ University of Lund, Sweden \\ henrik.sternberg@plog.lth.se
}

\author{
Giulia Baruffaldi \\ University of Padua, Italy \\ University of Bologna, Italy \\ giulia.baruffaldi2@unibo.it
}

\begin{abstract}
Due to the disruptive role of the Bitcoin in the financial sector, both scholars and practitioners are increasingly wondering whether it is possible to replicate the impact of the Blockchain technology in the supply chain context. As a distributed ledger technology characterized by the decentralized consensus, Blockchain is touted by many as the proper platform to collect all the information about supply chains from the producer to the consumer. However, the current technology immaturity and the lack of successful supply chain implementations pave the way for doubt about the disruptive role of this technology in supply chains. To the authors' knowledge, this work is one of the very first attempts to link the blockchain technology to supply chain and logistics. This paper investigates the state-of-the-art application of blockchain in supply chains, exploring both the literature and the industry initiatives, contributing to the increase of the managerial insight and providing a future research agenda.
\end{abstract}

\section{Introduction}

Few information technologies are gaining as much as attention as blockchains (BC). Though the main application of the blockchain technology is the Bitcoin currency [26], thousands of startups are innovating on novel blockchain applications in various industries, such as healthcare [40] and insurance [23]. Several initiatives, e.g., Provenance.org, are in mainstream media [44], riding on the trend of the increasing pressure to disclose supply chain information [21].

Several experts and industry speakers outline blockchains as a disruptive technology [8][37][42]. Bridget van Kralingen, Senior Vice President, Industry Platforms, IBM, said: "We believe that this new supply chain solution will be a transformative technology with the potential to completely disrupt and change the way global trade is done” [33].
Hence researchers, non-governmental organizations, and supply chain actors alike are all turning their attention to the blockchain diffusion. Several conferences are hosting blockchain tracks and Journal of Business Logistics just announced a special issue on the topic of blockchains [47]. This paper aims to outline blockchains in a supply chain perspective and address the question: Will blockchains have a disruptive effect on supply chains? More specifically we want to outline a realistic scope of the BC technology to aid practitioners and researchers in future implementation and diffusion.

To answer this question and outline a scope of the blockchain technology, we first elaborate on what the blockchain technology is and the differences between various types of blockchains. We then cover state of the art of blockchains in supply chains. That is followed by an empirical account of an ongoing blockchain pilot project, ReLog (http://trnsp.com/), and the challenges from the various stakeholders involved in this project. The insights from the pilot are followed by an application of logical reasoning to scope the technology. Finally, we discuss our conclusions aiding future adoption in supply chain management and logistics and propose future research questions.

The nature of this work is conceptual, as there, to the best of our knowledge, does not exist any actual supply chain implementation of blockchain technology. Though previous research encourages chief technologists to pursue "hot technologies" [30], that applies only to technological concepts that were implemented, not technological concepts that never reached implementation [36].

\section{Introduction to blockchain}

Firstly, an anonymous creator with the pseudonym of Satoshi Nakamoto with Bitcoin [27] introduced the shared ledger paradigm. Nakamoto was able to solve the cryptographic researchers' Byzantine General Problem [20], proposing an 
original system for electronic transactions which overcomes the need to rely on trusted authorities to ensure the 'honesty' of participants at the transaction through a decentralized consensus based on proof-ofwork. However, the first use of the term "shared ledger" to indicate any database, ledger, and application that is shared by an industry, a private consortium, or that is open to the public is claimed by Richard Brown, Chief Technology Officer of the Distributed Ledger Group [24]. As stated in [14], shared ledger technologies provide an original framework that has the potential to radically change business collaboration across several sectors, among them: finance, healthcare, and supply chain.

The activities and applications of blockchain are classified by Swan [37] in three broad categories: (1) Blockchain 1.0 embeds all the aspects related to currency and digital payment systems, e.g. Bitcoin, (2) Blockchain 2.0 includes economic, market, and financial applications that extend Blockchain 1.0, e.g. smart contracts, (3) Blockchain 3.0 is all applications beyond (1) and (2), e.g. government, art, and health. In illustrating (3), Swan hypes the extensibility of blockchain as the potential deployment of the blockchain core technology concepts in every field. In particular, the author claims how blockchain introduces a new conceptual paradigm in computing [38], which involves the distributed ledger and the decentralized consensus. As of today, there is no unified terminology and many sources use the terms 'block chain', 'blockchain', ‘distributed ledger' and 'shared ledger' interchangeably [42].

According to the Report of Credit Suisse [8], three main properties or levels of a ledger of digital records or transactions exist: the number of copies, the reader, and write access. A unique centralized copy of a ledger characterizes the traditional systems, (e.g. in government, in the current banking system and in large corporations), while a distributed ledger is an asset database that is shared across the nodes of a network, the peers [14]. All participants, who are connected to the peers (through a one-by-one connection) and are executing on behalf of the business they are working for, have their own identical copy of the ledger. Any changes are sent to all the copies (in a time step between a few seconds to a few minutes) making the ledger auditable. Moreover, distributed ledgers are decentralized in order to eliminate the need of a unique trusted authority and enhance robustness [34]. The reader access distinguishes between public ledgers, i.e. all participants can view the ledger, and a version of the ledger with a more restricted access, i.e. private. Private ledgers can be decentralized but not distributed. The last level corresponds to the authorization of the node to take part of the consensus mechanism. If all the nodes of the network can join the consensus mechanism the ledger results unpermissioned, otherwise is permissioned. In the latter case, the Report's authors compare the network with a hub and spoke model [2]. Bitcoin blockchain is one type of unpermissioned public ledger.

Vitalik Buterin classifies the Bitcoin blockchain as "public blockchain" to indicate an unpermissioned public ledger, distributed and characterized by low efficiency (due to a resource consuming mining process) and immutable stored transactions [5]. To perform the validation of transactions the Bitcoin blockchain relies on a decentralized consensus mechanism among the nodes of the network. In other words, once approved by the network transactions can be updated on the blockchain where it cannot be tampered with. Thus, ensures the reliability and the security of data. Two other types of blockchains are increasingly used in proof of concepts and startups: consortium and private blockchains. Consortium blockchains are partially decentralized permissioned ledgers where the reader access can be both public and restricted to a group of participants. In private blockchains the consensus process is restricted to only one organization [45]. Due to the fact that private blockchains can no longer be decentralized [48], some blockchain experts do not consider it as a “proper blockchain”, but still, as a type of distributed ledger technology (DLT) [28].

\section{State of the art: Blockchains in supply chains}

This section will outline the industry and research initiatives pertaining to blockchains and supply chain management (SCM). It should, however, be noted that while Gartner's 2017 hype curve places blockchain near the peak of the slope, it is still sliding downward on that slope [7], i.e., moving away from the expectations of being [a universal or an umbrella or a blanket] technology.

\subsection{Industry initiatives}

With regard to practitioners, some new-born startups that exploit blockchain for product traceability [25] are achieving a lot of visibility. This is the case of Provenance, which in July 2016 started to work with the UK's retailer Co-op in order to track fresh food, such as fish, eggs, and dairy, through its supply chain [44]. Co-op customers are able to access information on the product journey through an app on their smartphones. Through deploying blockchain 
technology while collaborating with external certifiers and auditors, i.e. non-governmental organizations certifying socially sustainable fishing, Provenance meets the increasing interest of customers for proven attributes of products (e.g. safety, local, fair trade, environmentally sustainable) [4].

In October 2016, the large retail organization Wal-Mart, IBM, and Tsinghua University signed an agreement aided to explore the opportunities of blockchain in food authentication and supply chain tracking [15], Walmart becoming one of the 400 IBM clients testing blockchain technology (March 2017). That same month, the New York Times announced that Maersk was up to use the IBM version of blockchain to track avocados, flowers, and machine parts on its cargo ships. In addition to realizing an effective traceability system, another aim of Maersk was reducing the paperwork (e.g. documents, approvals, stamps, etc.) related to each container which previously required the involvement of as many as 30 people [32]. Furthermore, IBM, which has around 650 employees dedicated to the application of blockchain technology, has recently included new features in its IBM Watson IoT Platform that enable IoT devices to send data to private blockchain ledgers. Use cases include data recording (position, arrival times, and status of shipping containers) and environmental condition (i.e. temperature and humidity) monitoring during freight transportation, component tracking, and compliance, and log operational maintenance data [16]. Another example is the startup company Modum.IO (pilot project launched in June 2016), whose purpose is the monitoring of temperature and humidity values experienced by medical products during shipments that do not require refrigeration [6]. Upon the arrival at the depot of destination data is transferred to the Ethereum blockchain, where specific smart contracts monitoring the temperature compliance with the extant regulations [9]. However, the current investigation of the effective benefits generated by the application of blockchain to the logistic field is still at an explorative stage. Furthermore, Reyes reports how DLT are currently under many regulatory discussions [35]. The lack of effective regulations affects the spread of new uses of DLT, for instance, with the application of unfitting payment laws. In January 2016, Mark Walport, as the UK's Government's Chief Scientific Officer, point outs the need for a regulatory framework for DLT, which should result from the joint work of academia, industry, and governmental institutions. Such framework should be able to follow the rapid evolvement in the use of this technology [42].

\subsection{Research on blockchains in supply chains}

Peters et al. [29] assess the use of blockchain as a ledger to record all the ownership details of physical assets (e.g. Everledger). Consequently, as a public ledger, blockchain could enhance the information transparency on products and processes along the whole supply chain (SC) [3]. Furthermore, the prerogative of blockchain of creating a trustless environment could impact business processes integration [43] and, consequently, on operational and business performance [10]. In 2017, Korpela et al. proposed to use blockchain to accelerate the transition to digital supply chains (DSC) [17], favoring the strategic sharing of information between all SC actors, improving coordination, communication, and processes integration. Yuan and Wang [46] are the first to discuss the potential advantages of blockchain in transportation research. They hype blockchain as the proper infrastructure to store and manage data from the physical space by integrating such technology into the IoT architecture to support the digitalization of the physical entities (e.g. roadside devices, vehicles, assets). Key IoT technologies, such as RFID and sensors, can provide a considerable amount of data that has to be managed in order to ensure data security and, importantly, confidence in the data quality. Thus, the trustless environment paradigm and the use of smart contracts seem to provide a charming solution [13]. In their work, Mattila et al. [22] explored the opportunities of using blockchain to support product-centric information management in order to provide an effective architecture to collect data on products over their entire life-cycle. The combined use of RFID and blockchain is also explored by Tian to enable track and tracing of products in the Chinese agri-food market in order to enhance food safety and quality while reducing food waste [39]. Abayratne and Monfared discuss the potential benefits of the application of blockchain to a manufacturing supply chain for cardboard boxes [1]. The authors point out the mutual advantages achieved by customers, who can easily access a great deal of data on products from the forestry to the waste recycler, and organizations, which can improve the control of processes and the security of transactions through the usage of smart contracts. Encouraged by the fact that a broader accepted key-driver for successful Supply Chain Finance (SFC) programs is the development of technological solutions favoring the collaboration among businesses and the speed-up of cash flows, Hofmann et al [12] explore the potential benefits of the introduction of blockchain-based solutions to SCF. While agreeing in claiming that BC would not 
scatter the rules of SCF, the authors underline how BC technology could enable SFC to speed up processes, make leaner structures and offer lesscostly services. Particularly, they estimate blockchain would simplify the onboarding of suppliers onto SCF platforms, favoring the inclusion of the long-tail supplier-base. Moreover, BC based platform allowing the issuance of trade related documents could affect SFC improving the ability to track the goods flows and leading to faster payments.

\section{Research design}

This paper reports findings from an ongoing development effort focusing on transparency in the transport industry. The goal is to explore the potential of utilizing distributed ledger technology together with the existing systems.

The solution was presented and discussed in numerous meetings and in two major workshops. Table 1 provides an outline of the people involved thus far.

Table 1. Data sources

\begin{tabular}{|c|c|}
\hline Retailer 1 & $\begin{array}{l}\text { Head of logistics development } \\
\text { Logistics developer } \\
\text { Logistics CSR } \\
\text { Head of transport purchasing }\end{array}$ \\
\hline Retailer 2 & $\begin{array}{l}\text { Logistics developer } \\
\text { Terminal manager }\end{array}$ \\
\hline LSP 1 & $\begin{array}{l}\text { Head of quality } \\
\text { Logistics developer (2) } \\
\text { Head of network planning } \\
\text { Account manager }\end{array}$ \\
\hline LSP 2 & $\begin{array}{l}\text { Integration analyst } \\
\text { Project manager (2) }\end{array}$ \\
\hline LSP 3 & Account manager \\
\hline Haulier association & $\begin{array}{l}\text { CEO } \\
\text { Head of member relations }\end{array}$ \\
\hline $\begin{array}{l}\text { Environmental } \\
\text { association }\end{array}$ & $\begin{array}{c}\text { Head of freight sustainability } \\
\text { certification }\end{array}$ \\
\hline $\begin{array}{l}\text { Transport booking } \\
\text { provider }\end{array}$ & $\begin{array}{l}\text { Head of enterprise customers } \\
\text { Account manager } \\
\text { Integration analysts (2) }\end{array}$ \\
\hline
\end{tabular}

\begin{tabular}{|l|l|}
\hline Municipalities & $\begin{array}{l}\text { Purchasing officers (2) } \\
\text { Freight planner }\end{array}$ \\
\hline Technology provider & $\begin{array}{l}\text { Technology executive } \\
\text { Nordic blockchain leader } \\
\text { Lead architect }\end{array}$ \\
\hline $\begin{array}{l}\text { Technology } \\
\text { consultancy }\end{array}$ & $\begin{array}{l}\text { Technical architect } \\
\text { Head of innovation } \\
\text { Technical project leader }\end{array}$ \\
\hline
\end{tabular}

Over the course of this project, numerous meetings and conversations took place within the core team (consisting of the university researcher and the technical project leader), often on a daily basis.

To strengthen the validity of this conceptual research, the technical project leader of the project read two versions of this paper as well as other more condensed industry magazine articles. After his first read, he suggested adding the section with the logical reasoning.

\section{ReLog}

The concept of ReLog ${ }^{1}$ is to create an information disclosure program (IDP) for supply chain transparency [20] by disclosing and logging of individual and organizational identities in a blockchain. ReLog resembles the concept of Provenance.org but with a focus on the links and nodes between the point of production and the point of consumption rather than focusing on the production.

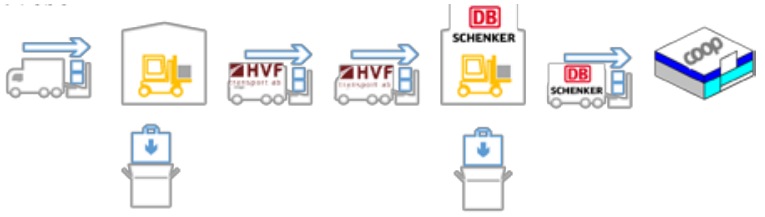

Figure 1. Sample goods flow

The researchers met with the various stakeholders in numerous workshops, meetings, and interviews (Table 1) and the main challenges that came forth were the following.

System integration. Creating a system integration for a specific goods flow (i.e., connecting it to a blockchain) with existing legacy systems is very challenging. The LSPs emphasized that the business

\footnotetext{
${ }^{1}$ The ReLog prototype video can be found here:

https://www.youtube.com/watch?v=nWVdg6KU1MI\&t=29s)
} 
case needs to very strong to motivate such an integration.

Transport worker privacy. Head of the Swedish transport union emphasized that even though the unions are, in general, positive to the idea of transparency, the privacy of the transport workers need to be investigated more thoroughly before a large-scale adoption can be fully supported.

Transport worker involvement. The transport booking company is very positive to the approach but as one account manager said in the workshop: "I do not want to be the party pooper, but already today it is a challenge to make the drivers update goods statuses with existing systems and you will need to find out a way how to engage them”.

Value and visualization. The retailers were also very positive about sharing their supply chains but were unsure about the value the additional information sharing towards customers would provide.

Need for blockchains. "The benefits of using blockchains in your solution (note: referring to the ReLog application) is long-term because it will enable you to distribute trust faster in the long run”, replied the lead technologist after discussing the architecture of the solution with the technical project leader. ReLog initially started out as a pilot project exploring the use of blockchains in supply chains, but in the summer of 2017, the team decided to abandon the technology due lack of usefulness. "Blockchain creates digital trust, not physical monitoring”, says the lead programmer in the discussion leading up to the decision to abandoning the blockchain architecture.

The next section will explain the logic of blockchains in SCM.

\section{Logic of blockchains in SCM}

In this section, we discuss blockchains using logic as related to naming and necessity [18]. This is necessary to determine what information technology actually means in terms of practical implications in supply chain.

\subsection{Facts (ledger/blockchain)}

Facts are an accurate and complete description of our universe - we can call it log, ledger, history. Assume we record every activity from creating identity/asset to transferring/aggregating/splitting assets. This fact set will be huge, but the structure is primitive -- facts form a simple, flat, and timestamped sequence of documents like this:
1. A created \{chocolate: 210 \}

2. A created \{coffee: 100$\}$

3. A transferred [\{coffee: 100\}, \{chocolate: 200\}] to C

4. C aggregated [\{coffee: 100\}, \{chocolate: 200\}] to \{shop_cage[ \{coffee: 100\}, \{chocolate: 200\}]: 1\}

5. C transferred \{shop_cage[ \{coffee: 100\}, \{chocolate: 200\}]: 1 \} to D

6. \{shop_cage[\{coffee: 100\}, \{chocolate: 200\}]: 1 \} is not active (delivered to destination)

7. $\{$ coffee: 100$\}$ is not active

8. $\{$ chocolate: 200$\}$ is not active

How do we add a new fact to the world's history? We must ensure consistency with all the past facts: if A wants to transfer asset XYZ to B, it must be a fact, A and B exists, A has XYZ (created or it was transferred to him/her and he/she did not forward it already), etc. If something is not consistent with what we regard as a fact, it cannot be a fact (it is not "true" about our world). We never alter any facts (we do not change history). We can only save a fact or read a fact.

Therefore, if A creates a \{chocolate: 210 that is not actually a true chocolate since the amount of cacao is too low in the recipe, the ledger does not help us. We will be able to see the history of transactions related to \{chocolate: 210 \}, but we will not know how the fake chocolate entered into the supply chain. This means that the trust of the authenticity of \{chocolate: 210 \} can never be larger than the trust that we have for actors A, B, C, and D.

\subsection{World state}

World state is a structure of all active assets/shipments and actors. World state answers one and only question "who has what right at this moment”, for example:

Identity A has \{chocolate: 10$\}$, \{candy: 12\}

Identity B has \{coffee_x001:1\}, \{coffee_x002:1\}

Identity C has \{shop_cage[\{coffee: 100\}, \{chocolate: 200\}]: 1$\}$ 
We can add a new fact if and only if it is consistent with the current world state. Adding a fact changes the current world state (the content of the fact says how exactly state is changed).

size of world state (only current active shipments) < size of fact set (everything, billions of shipments)

if we lost current world state we can re-create it by "replaying" all the facts since last saved world state.

\section{Concluding discussion}

Our paper set out to address the question: Will blockchains have a disruptive effect on supply chains? As of now, very little is known, as there is no actual running supply chain implementation of distributed ledger technology/blockchains. Literature and existing trials confirm the large potential and interest in the adoption of blockchain technology in supply chains, but given the current knowledge, some factors speak against a disruptive effect:

1. The logic of blockchains in supply chains give us that we either need a mechanism to establish physical trust, such as a reputation system or a central authority creating trust.

2. Industrial experience and our experiences in the ReLog project reveal that the integration of logistics activities and adoption of supply chain technology may not be straightforward.

3. Companies and individuals need to have clear incentives to implement and use blockchain technology. While some potential benefits are present, as of today, it is not apparent how they will be realized.

Our findings confirm the paper by Mattila et al [22], also questioning supply chain disruption by blockchain technology.

The extant literature has already identified a plethora of factors that influence organizations in the decision process on adopting a particular technology [19]. Some blockchain experts [31] believe that to increase the chances of success at larger scale, at first blockchain should be adopted by a few number of players representing a selected sample of key functions and sharing a common goal, i.e. a so-called minimal viable ecosystem. Thus, is in accordance with the statement introduced by Glaser claiming "the higher the closedness of the ecosystem, the more suitable is a blockchain infrastructure” [11]. Many organizations facing high environmental uncertainty are keener to adopt supply chain technologies, on the other hand, the lack of knowledge on blockchain long-term effects on supply chain makes a stable environment more suitable for its adoption. For example, a highly competitive environment determining frequent changing of SC actors may affect the decision process on how to allocate the blockchain costs along the supply chain [41], especially considering the blockchain characteristic of data persistency. Moreover, the trustless paradigm introduced by blockchain scatters the role of the transaction climate among SC actors as well as the debate about decentralization in technologies adoption.

As the public blockchain is unlikely to attract business interest, companies going forward with distributed ledger technologies are likely to resort to consortium and private blockchains [49].

\subsection{Future research}

1. Future research can expand the domain of the connection of the physical and digital world by considering the aforementioned logic of identities and trying to answer the question: Should the identities have to be physical identities? Moreover, we believe that the temperature monitoring protocol developed through the blockchain, as implied by Modum.Io, deserves special attention by actors of perishable products supply chain.

2. Further developments should deal with the management of distributed ledger/blockchain platform by multi-actor supply chains. Particularly, more efforts should be devoted to the management of the ownership of data [22] and the sharing of responsibility for the platform.

3. Potential future studies can also expand the lynchpin of blockchain success in the financial sector, which is its role in discarding the need for central authority [12]. The use of smart contracts in certifications might provide large value to supply chain finance.

\section{References}

[1] Abeyratne, S.A. and Monfared, R.P. "Blockchain ready manufacturing supply chain using distributed ledger." International Journal of Research in Engineering and Technology 5, 9 (2016), pp. 0-10.

[2] Arnäs, P.O., Holmström, J., and Kalantari, J. "In-transit services and hybrid shipment control: The use of smart goods in transportation networks." Transportation Research Part C: Emerging Technologies 36, (2013), pp. 231-244.

[3] Badzar, A. "Blockchain for securing sustainable transport contracts and supply chain transparency." 2016. http://lup.lub.lu.se/student-papers/record/8880383. 
[4] Brofman Epelbaum, F.M. and Martinez, M.G. "The technological evolution of food traceability systems and their impact on firm sustainable performance: A RBV approach." International Journal of Production Economics 150, (2014), pp. 215-224.

[5] Buterin, V. On Public and Private Blockchains. Ethereum Blog, 2015.

https://blog.ethereum.org/2015/08/07/on-public-andprivate-blockchains/ (Accessed February 2, 2017).

[6] Campbell, R. “Modum.io’s Temperature-Tracking Blockchain Solution Wins Accolades at Kickstarter Accelerator 2016”. Bitcoin Magazine, 2016. https://bitcoinmagazine.com/articles/modum-io-stempurature-tracking-blockchain-solution-wins-accoladesat-kickstarter-accelerator-1479162773/. (Accessed March 1, 2017)

[7] Columbus, L. “Gartner’s Hype Cycle for Emerging Technologies, 2017 Adds 5G And Deep Learning For First Time.” $\quad$ Forbes, 2017. https://www.forbes.com/sites/louiscolumbus/2017/08/15/ga rtners-hype-cycle-for-emerging-technologies-2017-adds5g-and-deep-learning-for-first-time/\#5acd319a5043. (Accessed September 2, 2017)

[8] Brennan, C., Lunn, W. "Blockchain: The Trust Disrupter.” Credit $\quad$ Suisse. 2016. https://www.finextra.com/finextra-

downloads/newsdocs/document-1063851711.pdf (Accessed February 5, 2017)

[9] European Commission. On Good Distribution Practice of medicinal products for human use. Official Journal of the European Union C 343, (2013), pp. 2001-2024.

[10] Flynn, B.B., Huo, B., and Zhao, X. "The impact of supply chain integration on performance: A contingency and configuration approach." Journal of Operations Management 28, 1 (2010), pp. 58-71.

[11] Glaser, F. "Pervasive Decentralisation of Digital Infrastructures: A Framework for Blockchain enabled System and Use Case Analysis." Proceedings of the 50th Hawaii International Conference on System Sciences (HICSS 2017), Hawaii, (2017), pp. 1543-1552.

[12] Hofmann, E., Strewe, U.M., and Bosia, N. Supply Chain Finance and Blockchain Technology -The Case of Reverse Securitisation. Springer International Publishing, 2018.

[13] Huckle, S., Bhattacharya, R., White, M., and Beloff, N. "Internet of Things, Blockchain and Shared Economy Applications." Procedia Computer Science 98, (2016), pp. 461-466.

[14] Hull, R., Batra, V.S., Chen, Y.-M., Deutsch, A., Heath III, F.F.T., and Vianu, V. "Towards a Shared Ledger Business Collaboration Language Based on Data-Aware Processes." Service-Oriented Computing: 14th International Conference, ICSOC 2016, Banff, AB, Canada, October 10-13, 2016, Proceedings, (2016), pp. 619.

[15] IBM. Walmart, IBM and Tsinghua University Explore the Use of Blockchain to Help Bring Safer Food to Dinner Tables Across China. IBM News room, 2016. https://www03.ibm.com/press/us/en/pressrelease/50816.wss (Accessed February 6, 2017).

[16] IBM. IBM Watson IoT - Private Blockchain. 2017. https://www.ibm.com/internet-of-things/platform/privateblockchain/ (Accessed March 5, 2017).

[17] Korpela, K., Hallikas, J., and Dahlberg, T., J. "Digital Supply Chain Transformation toward Blockchain Integration." Proceedings of the 50th Hawaii International Conference on System Sciences, Hawaii, (2017), pp. 41824191.

[18] Kripke, S. Naming and Necessity. Harvard University Press, Cambridge, Massachusetts, 1980.

[19] Kwon, T.H., Zmud, R.W., "Unifying the fragmented models of information systems implementation." In: Boland, R.J., Hirschheim, R.A. (Eds.), In Critical Issues in Information Systems Research. John Wiley, New York, pp. 247-252, 1987.

[20] Lamport, L., Shostak, R., and Pease, M. "The Byzantine generals problem." ACM Transactions on Programming Languages and Systems (TOPLAS) 4.3, (1989), pp. 382-401.

[21] Marshall, D., McCarthy, L., McGrath, P., and Harrigan, F. "What's Your Strategy for Supply Chain Disclosure?" MIT Sloan Management Review 57, 2 (2016), pp. 37-45.

[22] Mattila, J., Seppala, T., and Holmstrom, J. "Productcentric Information Management: A Case Study of a Shared Platform with Blockchain Technology." Industry Studies Association Conference (ISA2016), (2016), pp. 0144.

[23] McKinsey\&Company. Blockchain in insurance opportunity or threat? 2016. http://www.mckinsey.com/industries/financialservices/our-insights/blockchain-in-insurance-opportunityor-threat (Accessed February 2, 2017).

[24] De Meijer, C.R.W. "Blockchain, distributed and shared ledger, permissionless and permissioned: What's in a name!!" 2016. https://www.linkedin.com/pulse/blockchain-distributedshared-ledger-permissionless-whats-demeijer?articleId $=6125925523114721280$ February 5, 2017).

(Accessed

[25] Moe, T. "Perspectives on traceability in food manufacture". Trends in Food Science \& Technology 9, 5 (1998), pp. 211-214.

[26] Moody’s Investors Service. "Robust, Cost-effective Applications Key to Unlocking Blockchain's Potential Credit Benefits”, 2016. https://www.scribd.com/document/319012770/RobustCost-effective-Applications-Key-to-Unlocking-Blockchains-Potential-Credit-Benefits (Accessed February 15, 2017).

[27] Nakamoto, S. Bitcoin: A Peer-to-Peer Electronic Cash System, 2008. https://bitcoin.org/bitcoin.pdf. 
[28] O’Connell, J. "What Are the Use Cases for Private Blockchains? The Experts Weigh In." Bitcoin Magazine, 2016. https://bitcoinmagazine.com/articles/what-are-theuse-cases-for-private-blockchains-the-experts-weigh-in1466440884/ (Accessed February 6, 2017).

[29] Peters, G.W., Panayi, E., and Chapelle, A. "Trends in crypto-currencies and blockchain technologies: A monetary theory and regulation perspective." Journal of Financial Perspectives 3, 3 (2015), pp. 92-133.

[30] Wang, P. "Chasing the Hottest It: Effects of Information Technology Fashion on Organizations." Mis Quarterly 34, 1 (2010), pp. 63-85.

[31] Piscini, E. "Why 2017 is Blockchain’s Make or Break Year." Coin Desk, 2017. http://www.coindesk.com/why2017-is-blockchains-make-or-break-year/(Accessed February 2, 2017).

[32] Popper, N. and Lohr, S. "Blockchain: A Better Way to Track Pork Chops, Bonds, Bad Peanut Butter?" New York Times, 2017. https://www.nytimes.com/2017/03/04/business/dealbook/bl ockchain-ibm-bitcoin.html?_r=1.

[33] PORT Technology. Watch: IBM-Maersk Unite on Global Blockchain Initiative. 2017. https://www.porttechnology.org/news/watch_blockchain_di gitizing_global_logistics.

[34] Raval, S. "Decentralized applications: harnessing Bitcoin’s Blockchain technology.” O’Reilly Media, 2016.

[35] Reyes, C.L. "Moving Beyond Bitcoin to an Endogenous Theory of Decentralized Ledger Technology Regulation: An Initial Proposal." Villanova Law Review 61, (2016), pp. 191-234.

[36] Sternberg, H. and Andersson, M. "Decentralized intelligence in freight transport - A critical review". Computers in Industry 65, 2 (2014), pp. 306-313.

[37] Swan, M. Blueprint for a new economy. O’Reilly Media, 2015.

[38] Swan, M. "Blockchain Temporality: Smart Contract Time Specifiability with Blocktime." Rule Technologies. Research, Tools, and Applications: 10th International Symposium, RuleML 2016, Stony Brook, NY, USA, July 6-9, 2016. Proceedings, (2016), pp. 184-196.

[39] Tian, F. "An agri-food supply chain traceability system for China based on RFID \& blockchain technology." 2016 13th International Conference on Service Systems and Service Management, ICSSSM 2016, Kust, Kunming, China, (2016).

[40] Tierion. "Blockchain Healthcare Promise \& Pitfalls", 2016. https://tierion.com/blog/blockchain-healthcare-2016report/ (Accessed February 10, 2017)

[41] Vaughan, W. "2017’s Big Question: Who Pays for the Blockchain?" 2016. http://www.coindesk.com/2017question-who-pays-for-blockchain/ (Accessed February 2, 2017)

[42] Walport, M. Distributed ledger technology: Beyond block chain. UK Government Office for Science, (2016).

[43] Weber, I., Xu, X., Riveret, R., Governatori, G., Ponomarev, A., and Mendling, J. "Untrusted Business Process Monitoring and Execution Using Blockchain." International Conference Business Process Management (BPM), Rio de Janeiro, Brazil, September 2016.

[44] Wheeler, M. "The woman whose mum inspired her to track ethical food.” BBC News, 2017. http://www.bbc.com/news/business-38773878 (Accessed March 1, 2017)

[45] Xu, X., Pautasso, C., Zhu, L., Gramoli, V., Ponomarev, A., Tran, A.B., and Chen, S. "The blockchain as a software connector." Proceedings - 2016 13th Working IEEE/IFIP Conference on Software Architecture, WICSA 2016, Venice, Italy, (2016), pp. 182-191.

[46] Yuan, Y. and Wang, F. "Towards Blockchain-based Intelligent Transportation Systems." 2016 IEEE 19th International Conference on Intelligent Transportation Systems, ITSC 2016, Rio de Janeiro, Brazil, November 14, (2016), pp. 2663-2668.

[47] Zacharia, Z.G. JBL Newsletter Editor's Corner. Journal of Business Logistics 7, 2 (2017), 1-12.

[48] Zheng, Z., Dai, H.-N., Xie, S., and Wang, H. "Blockchain Challenges and Opportunities: A Survey." International Journal of Web and Grid Services, (2016), pp. $1-24$.

[49] The difference between a Private, Public and Consortium Blockchain. Blockchain daily news, 2016. http://www.blockchaindailynews.com/The-differencebetween-a-Private-Public-ConsortiumBlockchain_a24681.html (Accessed February 2, 2017). 